\title{
A CONVENÇÃo PELA ELIMINAÇÃo DE TODAS AS FORMAS DE DISCRIMINAÇÃO CONTRA A MULHER (CEDAW) E A CONDIÇÃO FEMININA NAS "SOCIEDADES OPRESSORAS CONTEMPORÂNEAS"
}

Fernanda Bernardo Gonçalves ${ }^{1}$

\section{RESUMO}

Tendo como norte a Convenção pela Eliminação de Todas as Formas de Discriminação contra a Mulher e a principiologia por ela inaugurada, o presente artigo tem por escopo problematizar a condição feminina em sociedades ditas opressoras, através de uma reflexão sobre a polêmica entre as concepções universalista e relativista de direitos humanos. Nesse sentido, serão analisados livros escritos por mulheres que viveram nessas sociedades, de modo a suscitar aspectos relevantes para o debate em curso.

\section{ABSTRACT}

Having the Convention on the Elimination os All Forms of Discrimination against Women and its principiology as a guideline, the present article has as a scope the discussion about the female condition in some so-called opressive societies, through a reflection about the polemic between the universalistic and the relativistic conceptions of the human rights. In this sense, some books written by women who lived in those societies will be analyzed in a way to promote relevant aspects for the current debate.

Indicadores: CEDAW, proteção internacional dos direitos das mulheres, universalismo e relativismo dos direitos humanos.

Keywords: CEDAW, international protection of women rights, universalism and relativism of human rights.

\footnotetext{
${ }^{1}$ Bacharela em Direito pela UFPR. Pesquisadora do Núcleo de Direito Internacional da UFPR "Mania de ter fé na vida": a condição feminina nas sociedades opressoras.
}

Revista Brasileira de Direito Internacional, Curitiba, v.6, n.6, jul./dez.2007 


\section{INTRODUÇÃO}

O presente trabalho versará sobre uma problemática do Direito Internacional dos Direitos Humanos, aplicada a um caso específico. Trata-se da polêmica universalismo versus relativismo dos direitos humanos, vista sob a perspectiva da defesa dos direitos das mulheres. Como norte, utilizar-se-á a Convenção pela Eliminação de Todas as Formas de Discriminação Contra a Mulher (Convention on the Elimination of All Forms of Discriminations Against Women - CEDAW, e a principiologia por ela inaugurada na proteção e reconhecimento da condição feminina, especificamente quanto à questão de gênero em sociedades ditas opressoras na contemporaneidade.

Neste artigo, problematizaremos a realidade de mulheres orientais que vivem sob padrões distintos daqueles vigentes em nossa sociedade, exemplificadas pela observação das realidades chinesa, muçulmana e africana, sem pretensão de exaustão do tema. As aspas do título justificam-se pelo fato de que, em relação à condição feminina, a mentalidade ocidental pode ser tão ou mais opressora que aquelas, objeto da presente pesquisa ${ }^{2}$. No entanto, mantemos a denominação, mesmo tendo em consideração o alerta acima mencionado, pelas condições extremas de tratamento dispensado às mulheres nessas sociedades.

A CEDAW representa mais uma forma de concretização dos direitos humanos no plano internacional, compondo o Sistema Global de Proteção aos Direitos Humanos da ONU. Nada obstante, discute-se se o documento não expressaria valores precipuamente ocidentais, a despeito de sua pretensão de universalidade.

É possível, então, pensar em compatibilizá-los aos valores das sociedades ditas opressoras no mundo contemporâneo, as quais relegam à

\footnotetext{
${ }^{2}$ Haja vista o recente relatório chinês acerca das constantes violações aos direitos humanos nos Estados Unidos (2004), o qual aponta diversos casos de violência sexual e física (Cf. GOYOS JÚNIOR, Durval Noronha. O Novo Direito Internacional Público e o Embate contra a Tirania, p. 119-121). Da mesma forma, a realidade brasileira encontra-se permeada de péssimos exemplos de discriminação e violência contra a mulher, ensejando inclusive a promulgação da Lei Maria da Penha. Por outro lado, a competitividade com os homens e a busca constante por um padrão de beleza são características das mulheres ocidentais que recebem críticas profundas de outras culturas, justamente por imporem ao sexo feminino verdadeira escravidão.
}

Revista Brasileira de Direito Internacional, Curitiba, v.6, n.6, jul./dez.2007 
mulher um papel secundário no contexto social, de forma a dar conta da necessidade premente de fuga das condições em que vivem as mulheres oprimidas? Responder sim à questão sem maiores considerações seria leviano, representando uma defesa aos padrões ocidentais das sociedades "civilizadas" e contribuindo para a destruição de culturas tão ricas. Mas respostas negativas podem ser tão perigosas, ao expressar uma concordância irrefletida com as teorias do relativismo dos direitos humanos. Não haveria algo de universal nos direitos humanos que permitiria reconhecer sua necessidade de proteção e afirmação a todas as pessoas, independentemente de sua origem? Especialmente no que tange à condição feminina oprimida por sociedades machistas?

Eis o escopo do presente trabalho, que se baseará em relatos reais de mulheres provenientes das sociedades que iremos investigar. Para tanto, partiremos de livros cujas histórias, à primeira vista chocantes se tomarmos como paradigma a sociedade liberal-ocidental, desvendam a alma feminina e denunciam as atrocidades cometidas contra o sexo feminino em nome do dogma da superioridade masculina.

Assim, primeiramente, analisaremos a CEDAW e seu significado na proteção de gênero, para, na parte final, após a análise dos relatos supra mencionados, discorrermos acerca das possibilidades de salvaguarda da dignidade e dos direitos das mulheres que vivem em sociedades opressoras.

Revista Brasileira de Direito Internacional, Curitiba, v.6, n.6, jul./dez.2007 


\section{A CONVENÇÃO PELA ELIMINAÇÃO DE TODAS AS FORMAS DE DISCRIMINAÇÃO CONTRA AS MULHERES - CEDAW}

A Convenção pela Eliminação de Todas as Formas de Discriminação contra as Mulheres foi firmada em 18 de dezembro de 1979, pela Resolução oㅡ 34/180 da Assembléia Geral das Nações Unidas, e faz parte do amplo rol de mecanismos internacionais de proteção aos direitos humanos, os quais, "de natureza e efeitos jurídicos distintos, tiveram o propósito e acarretaram a conseqüência de ampliar o alcance da proteção a ser estendida às supostas vítimas"3.

A CEDAW inclui-se no sistema global de proteção aos direitos humanos, no âmbito da Organização das Nações Unidas. Com pretensão de alcance mundial, o sistema global é encabeçado pela Declaração Universal dos Direitos Humanos de 1948, seguida pelos Pactos de $1966^{4}$ e pelas demais Convenções de Direitos Humanos. A idéia predominante é a de que o sistema global e os sistemas regionais se complementem, de forma a conceder às vítimas a efetiva proteção de seus direitos.

A concepção de que determinadas pessoas ou grupos mereciam proteção especial, pois os Tratados gerais de direitos humanos não eram capazes de compreender sua vulnerabilidade, representa o processo de especificação dos direitos humanos ${ }^{5}$ no plano internacional. Nas palavras de Flávia Piovesan:

O sistema especial de proteção realça o processo da especificação do sujeito de direito, em que o sujeito de direito é visto em sua especificidade e concreticidade. Isto é, as Convenções que integram este sistema são endereçadas a determinado sujeito de direito, ou seja, buscam responder a determinada violação de direito. ${ }^{6}$

\footnotetext{
${ }^{3}$ CANÇADO TRINDADE, Antônio Augusto. A proteção internacional dos direitos humanos: fundamentos jurídicos e instrumentos básicos, p. 1.

${ }^{4}$ Pacto Internacional dos Direitos Civis e Políticos e Pacto Internacional dos Direitos Econômicos, Sociais e Culturais.

${ }_{5}^{5}$ Cf. BOBBIO, Norberto. A era dos direitos, p. 68-69.

6 PIOVESAN, Flávia. Direitos Humanos e o Direito Constitucional Internacional, p. 202. semelhante entendimento expressa CANÇADO TRINDADE, A. A. A proteção internacional dos direitos humanos, p. 39: "A expansão e a generalização da proteção internacional dos direitos humanos também possibilitaram que se voltasse a atenção aos direitos atinentes a distintas categorias de pessoas protegidas, tidas como necessitadas de proteção especial, o que levou
}

Revista Brasileira de Direito Internacional, Curitiba, v.6, n.6, jul./dez.2007 
É nesse contexto que surge a CEDAW, compreendendo-se que o sexo feminino é vítima de diversas formas de discriminação ao redor do mundo, sendo que as mais cruéis consistem nas diversas formas de violência praticadas contra as mulheres, e que tal discriminação representa, muitas vezes, um padrão de conduta de sociedades marcadas pelo machismo e pelo patriarcalismo, como apontado pelo Relatório do Comitê de Ministros do Conselho da Europa:

(...) les caractéristiques particulières des violences exercées contre les femmes qui les différencient des autres types de violences : en effet, elles traduisent l'expression d'un rapport de domination d'un sexe sur l'autre et sont souvent davantage tolerées par le corps social: les violences concernant les filletes sont souvent les manifestations culturelles ou religieuses qui reprennent les mêmes schémas . ${ }^{7}$

Por essa razão, a CEDAW traz em seu artigo 1ำ uma definição ampla acerca do alcance de sua proteção, ao definir da seguinte maneira a discriminação contra o sexo feminino:

Para os fins da presente Convenção, a expressão "discriminação
contra as mulheres" significa toda distinção, exclusão ou restrição
fundada no sexo e que tenha por objetivo ou conseqüência prejudicar
ou destruir o reconhecimento, gozo ou exercício pelas mulheres,
independentemente do seu estado civil, com base na igualdade dos
homens e das mulheres, dos direitos humanos e liberdades
fundamentais nos campos político, econômico, social, cultural e civil
ou em qualquer outro campo.

A Convenção estabelece uma série de deveres aos Estados-partes, no sentido de que atuem internamente de forma a eliminar progressivamente a discriminação contra as mulheres, não apenas abstendo-se de práticas discriminatórias no âmbito público, mas promovendo a igualdade substancial entre os gêneros também nas relações privadas. Em seus dispositivos, há o

ao enunciado de, e.g., direitos dos trabalhadores, direitos dos refugiados, direitos das mulheres, direitos da criança, direitos dos idosos, direitos dos inválidos".

${ }^{7}$ Cf. CONSEIL DE L'EUROPE. La protection des femmes contre la violence: Recommandation Rec (2002) 5 du Comité des Ministres aux Etats membres sur la protection des femmes contre la violence adoptée le 30 avril 2002 et Exposé des motifs, p. 172 .

Revista Brasileira de Direito Internacional, Curitiba, v.6, n.6, jul./dez.2007 
reconhecimento de que as distorções existem em diversos âmbitos da vida social, como no que se refere aos costumes e à educação, no trabalho, na proteção à saúde da mulher, nas relações familiares e matrimoniais, na aquisição e administração de bens e na proteção contra a exploração e a prostituição. Por isso, prevê como deveres dos países a modificação das estruturas legislativas e a introdução de mecanismos afirmativos como forma de defesa e promoção do status da mulher nos países signatários.

Como mecanismos de monitoramento do cumprimento de suas disposições, a CEDAW prevê o Comitê para Eliminação da Discriminação contra as Mulheres, formados por vinte e três peritos provenientes dos países signatários, para o qual os Estados-partes devem enviar a cada quatro anos, ou quando solicitados, relatórios informando acerca das medidas tomadas para assegurar os direitos previstos pela Convenção ${ }^{8}$. Em 1999, a ONU adotou o Protocolo Facultativo à CEDAW, que permite o reconhecimento da jurisdição do Comitê para receber petições individuais com reclamações sobre violações à Convenção ${ }^{9}$.

Atualmente, 185 Estados são signatários da CEDAW, o que perfaz um total de mais de $90 \%$ dos membros das Nações Unidas. Entretanto, justamente por seu caráter abrangente, buscando a proteção integral dos direitos das meninas e mulheres, a Convenção pela Eliminação de Todas as Formas de Discriminação contra a Mulher é o tratado de direitos humanos no âmbito da ONU com maior números de reservas aos seus dispositivos, sendo que muitas delas acabam por comprometer a aplicação mesma da CEDAW, pois tais Estados não se obrigam a garantir em seu território direitos essenciais à dignidade da condição feminina. Sua pretensão de universalidade, portanto,

\footnotetext{
${ }^{8}$ Segundo Andrew Byrnes, In: STEINER, Henry J.; ALSTON, Philip. International Human Rigths in context: Law, Politics, Morals, p. 188: “(...) the CEDAW Committee was constituted as a body os independent experts given the task of monitoring states' efforts to meet their obligations through review of periodic reports submitted by the states parties. The Committee's importance has steadily increased over its life, partly as a consequence of the greater attention given women's rights on the world scene, from world conferences to new international instruments."

9 Cf. CENTRO DE JUSTIÇA GLOBAL. Programa de Capacitação "Marcio Baccarin Possebon": Treinamento em mecanismos internacionais de direitos humanos e estratégias de mídia, p. 4: "Trata-se de um importante instrumento jurídico para garantir o acesso às mulheres aos mecanismos internacionais de proteção de forma eficaz e direta, quando o sistema nacional se mostrar falho ou omisso no que se refere aos direitos humanos consagrados na Convenção."
}

Revista Brasileira de Direito Internacional, Curitiba, v.6, n.6, jul./dez.2007 
coloca em xeque-mate exatamente a aplicabilidade de seus princípios e dispositivos.

Essa situação mostra quão complexa é a proteção dos direitos humanos das mulheres no plano internacional, bem como a garantia de um núcleo mínimo de direitos das quais possam gozar. A Declaração de Viena, documento final da Conferência de Direitos Humanos de 1993, assim dispõe acerca da temática:

\begin{abstract}
Ações e medidas para reduzir o amplo número de reservas à Convenção devem ser encorajadas. Dentre outras medidas, o Comitê de Eliminação de Todas as Formas de Discriminação contra a Mulher deve prosseguir na revisão das reservas à Convenção. Os Estados são convidados a eliminar as reservas que sejam contrárias ao objeto e ao propósito da Convenção, ou que sejam incompatíveis com os tratados internacionais.
\end{abstract}

A retirada urgente das reservas substanciais feitas à CEDAW por diversos países é apenas uma das muitas medidas necessárias à salvaguarda dos direitos das mulheres ao redor do mundo.

Como referido alhures, a problemática relativa aos direitos humanos do sexo feminino requer várias providências rumo à erradicação da discriminação de gênero. Nesse sentido, muitos temas se entrelaçam e aparecem continuamente nas discussões sobre a questão feminina, e sobre ela exercem influência, tais como: normas e costumes dos diferentes países, que podem relegar a questão à tradição, compreendendo o tratamento dispensado às mulheres como sinônimo de garantia de preceitos morais; mudanças sócioeconômicas, direcionando a mulher ao mercado de trabalho, o que implica em modificações nas estruturas de família e matrimoniais ${ }^{10}$.

De igual modo, outras situações atingem as mulheres de forma diferente, e mesmo mais severa, que os homens. É o caso, por exemplo, das zonas de conflito, onde muitas vezes estupros e violências são utilizados como forma de coerção da população. Nas situações de pobreza extrema, igualmente, às mulheres são negados remédios e alimentos, numa

${ }^{10}$ Cf. STEINER, H.; ALSTON, P. International Human Rigths in context.

Revista Brasileira de Direito Internacional, Curitiba, v.6, n.6, jul./dez.2007 
demonstração de discriminação que coloca o sexo feminino em posição de inferioridade frente ao masculino ${ }^{11}$.

É para fazer frente a situações como essas, dentre tantas outras, que a CEDAW assume importância crucial na defesa da igualdade de tratamento à mulher. Diante de inúmeros casos de discriminação aberta, corroborados pela religião e pelos costumes, de denúncias de maus-tratos a esposas e filhas, de casamentos forçados, danos à integridade física, ou mesmo assassinatos ${ }^{12}$, não há dúvidas de que a situação da mulher ao redor do planeta merece uma maior atenção por parte da comunidade internacional.

Nesse sentido, a análise da condição feminina em sociedades conhecidas por subjugar a mulher ganha relevo, permitindo o conhecimento da situação rela dessas mulheres e meninas, tão distantes de nós geograficamente, mas cuja dor e sofrimento tornam-nos próximas e solidárias.

${ }^{11}$ Cf. In: CONSEIL DE L'EUROPE. La protection des femmes contre la violence, p. 18: "Certaines situations économiques difficiles (engendrant chômage et paupérisation), les crises politiques et les conflits armés (à l'origine de flux migratoires importants) fonctionnent comme des facteurs aggravants, dans la mesure où les femmes, se trouvant souvent dans des situations précarisées, deviennent les cibles privilégiées du système."

${ }_{12} \mathrm{O}$ Comitê de Direitos Humanos da ONU, emitiu um Relatório em 2000, abordando a igualdade de oportunidades de gozo dos direitos expressos pelo Pacto Internacional dos Direitos Civis e Políticos, concluindo que os Estados precisam adotar uma série de medidas para assegurar a proteção do sexo feminino contra a discriminação nos mais diversos setores da vida social. Cf. HUMAN RIGTHS COMMITTEE. General Comment № 28: Equality of rights between men and women, (Art. 3), 2000.

Revista Brasileira de Direito Internacional, Curitiba, v.6, n.6, jul./dez.2007 


\section{A CONDIÇÃO FEMININA NAS SOCIEDADES OPRESSORAS}

Apresentamos agora relatos reais acerca da vida em sociedades onde a condição feminina é extremamente inferiorizada frente aos homens, e onde as condutas machistas constituem-se em standard de comportamento. Não há a pretensão de esgotar os assuntos apresentados pelas obras de referência; todavia, preocupamo-nos em suscitar os aspectos mais relevantes para o tema exposto, de forma a dar vida ao clamor de mulheres que não desistem de lutar.

\subsection{A CONDIÇÃO DE MULHER NA CHINA REVOLUCIONÁRIA}

Nosso ponto de partida é a realidade das mulheres chinesas, contada pela jornalista Xinran, no livro As Boas Mulheres da China. A autora viveu em Pequim, onde apresentava um programa de grande audiência em uma rádio estatal chinesa, o "Palavras na brisa noturna". Nele, Xinran lia cartas enviadas por mulheres de todo o País, nas quais elas contavam suas histórias, seus dramas, e realizavam suas denúncias contra o sistema opressor e violento ao qual eram submetidas. Com a intenção de publicar as histórias que mais the chamaram a atenção, e consciente de que o governo chinês jamais permitiria tal afronta, a jornalista abandonou Pequim e mudou-se para Londres, onde publicou o livro que agora apresentamos.

O livro retrata a condição feminina em uma China ainda fortemente marcada pela Revolução Cultural, levada a cabo para a instauração do regime comunista no país. Os anos 60/70 representaram o auge da Revolução, onde o regime buscava livrar a China de qualquer influência capitalista. A partir dos anos 80 , o país entra em um período de maior abrandamento nos costumes; contudo, os anos rígidos jamais serão esquecidos.

Sobretudo no que tange à proteção da mulher contra a violência sexual e à discriminação. A rígida moral chinesa, vigente no período prérevolucionário, impunha a submissão das mulheres a seus pais e maridos. Somada ao regime político que se instalou, fortemente autoritário e invasivo no que se refere à vida privada dos chineses, o resultado foi a perpetuação da 
cultura machista e a destruição do direito à intimidade das chinesas, expostas a crimes sexuais, casamentos forçados (por vezes em nome da Revolução), e ao mais completo abandono por parte do frágil sistema legal. É Xinran quem descreve:

De modo geral foram as crianças, sobretudo as meninas, que arcaram com as conseqüências do desejo sexual frustrado. A menina que cresceu durante a Revolução Cultural viu-se cercada de ignorância, loucura e perversão. As escolas e as famílias eram incapazes e proibidas de lhes dar a mais elementar educação sexual. Muitas mães e professoras também eram ignorantes nesses assuntos. Quando a menina amadurecia, a menina se tornava vítima de ataques indecentes ou estupro (...) Os perpetradores foram seus professores, amigos, até seus pais e irmãos, que perderam o controle dos instintos animais e agiram da maneira mais feia e egoísta de que um homem pode agir. As esperanças das meninas foram destruídas, e sua capacidade de sentir o prazer de fazer amor foi danificada para sempre. Se pudéssemos ter acesso aos pesadelos delas, passaríamos dez ou vinte anos ouvindo o mesmo tipo de história. ${ }^{13}$

É essa posição de inferioridade que faz uma garota de apenas dezessete anos, que se entrega à morte para não sofrer mais os abusos de seu pai, perguntar-se: "O que são as mulheres exatamente? Os homens devem ser classificados exatamente na mesma espécie que as mulheres? Por que é que eles são tão diferentes? ${ }^{14}$.

A diferença brutal entre homens e mulheres, contudo, não é demonstrada somente através da repressão e dos abusos sexuais sofridos por meninas e mulheres, resultado de uma educação machista e repressora, mas que também fora utilizado sistematicamente como meio de tortura das mulheres cujas famílias eram consideradas descendentes de capitalistas.

Essas "boas mulheres" também sofreram sérios abalos em sua estrutura individual e familiar, em nome do regime comunista. Muitas vezes, as mães tiveram os filhos arrancados de seus braços, entregando-os para serem educados pelos revolucionários, enquanto elas próprias serviam ao Estado em outro ponto do país. Essas mães, quando seus casamentos não foram arranjados pela família ou pelo Partido, ocupavam uma posição apenas de

\footnotetext{
${ }^{13}$ XINRAN. As boas mulheres da China: vozes ocultas, p. 235-236.

${ }^{14}$ XINRAN. As boas mulheres da China, p. 46.
}

Revista Brasileira de Direito Internacional, Curitiba, v.6, n.6, jul./dez.2007 
coadjuvante ao lado do marido, numa vida repleta de deveres, mas sem amor. A moral rígida imposta às chinesas legitima desde as agressões físicas às companheiras, até a condenação pública de mulheres mais liberadas sexualmente ou de homossexuais, chegando às raias de determinar a prisão delas pela violação dos costumes.

$\mathrm{Na}$ última história do livro, são problematizadas a pobreza extrema e a ignorância das mulheres, em uma região da China conhecida como "Colina dos Ventos"; justamente por essas razões, afirma Xinran, "as mulheres da Colina dos Gritos foram as únicas a me dizer que eram felizes" ${ }^{\text {"15 }}$.

\subsection{A REVOLTA SILENCIOSA DAS MULHERES DO IRÃ}

Lendo Lolita em Teerã é um belo livro escrito pela professora de Literatura Azar Nafisi, acerca da vida das mulheres no Irã após a Revolução Islâmica que levou o Aiatolá Khomeini ao poder. Vivendo hoje nos Estados Unidos, a autora conta a história iraniana nos tempos mais difíceis da Revolução, quando o regime teocrático endureceu o respeito aos costumes, submetendo mulheres que, até então, levavam uma vida livre e em posição de igualdade (ao menos formal) com os homens.

O regime foi marcado por ciclos de maior ou menor tolerância, mas sempre mesclando religião e poder, com a imposição da moral islâmica à população, que à época não era formada apenas por muçulmanos. As Universidades, no início proibidas de funcionar, logo se tornaram centros de disseminação do regime político, com a vigilância constante de professores e alunos, bem como dos conteúdos ministrados.

Azi (apelido da autora) era professora da Universidade de Teerã e de lá foi expulsa por recusar-se a lecionar usando o chador, vestimenta que cobre os cabelos e quase a totalidade do corpo da mulher. Voltou a ministrar aulas em outras Universidades, somente quando aceitou submeter-se às regras impostas pelo regime.

${ }^{15}$ XINRAN. As boas mulheres da China, p. 275.

Revista Brasileira de Direito Internacional, Curitiba, v.6, n.6, jul./dez.2007 
Durante aproximadamente dois anos, a professora reuniu em sua casa um grupo de mulheres iranianas que haviam sido suas alunas na Universidade, com o fim de praticar uma transgressão silenciosa: a leitura de obras literárias ocidentais. Por meio de livros como O grande Gatsby, Orgulho e Preconceito, e, especialmente, Lolita, essas mulheres reunidas em uma sala de estar não estavam diretamente interessadas no confronto direto com o governo, mas sim em recuperar aquilo que o regime autoritário tentava roubar, qual seja, a capacidade de imaginar. É Azar Nafisi quem escreve:

\begin{abstract}
Nos que vivemos na República Islâmica tanto a tragédia quanto o absurdo da crueldade aos quais éramos submetidos. Nos tínhamos que achar graça em nossa própria miséria para sobreviver. Também reconhecíamos instintivamente o poshlust - não somente nos outros, mas em nós mesmos. Essa era a única razão pela qual a arte e a literatura se tornaram tão essenciais para nossas vidas: não eram luxo, mas necessidade. O que Nabokov capturou foi a textura da vida numa sociedade totalitária, onde se está completamente sozinho num mundo ilusório cheio de falsas promessas, onde não se pode mais diferenciar entre seu salvador e seu carrasco. ${ }^{16}$
\end{abstract}

O autoritarismo do novo regime impôs às mulheres a observância estrita dos valores islâmicos, da forma como o governo os interpretava. Havia, inclusive, um grupo denominado "Sangue de Deus", formado por mulheres e homens armados, e que tinham por tarefa "assegurar que as mulheres (...) vistam seus véus adequadamente, não usem maquiagem, não caminhem em público com homens que não sejam seus pais, irmãos ou maridos"17. A imposição do uso do véu representou a maior expressão da opressão sofrida pelas mulheres. A prática, que antes da Revolução era o modo de as muçulmanas manifestarem sua fé e sua religião, com a obrigatoriedade, transformou-se em ato político, concebido como marca do regime teocrático.

Como relata a autora, naqueles tempos, a idade para o casamento foi diminuída para nove anos, o adultério e a prostituição voltaram a ser punidos com a morte por apedrejamento, e a lei estabelecia que uma mulher valia a metade de um homem. Para a condição feminina, foi um retrocesso

\footnotetext{
${ }^{16} \mathrm{NAFISI}$, Azar. Lendo Lolita em Teerã: uma memória nos livros, p. 45.

${ }^{17}$ NAFISI, A. Lendo Lolita em Teerã, p. 49.
}

Revista Brasileira de Direito Internacional, Curitiba, v.6, n.6, jul./dez.2007 
significativo, vez que a geração anterior de mulheres pôde escolher seu marido, estudar livremente, e sair às ruas sem medo de ser considerada imoral.

Nas últimas páginas do livro, Azar Nafisi noticia a lenta mudança em sua terra natal, por meio da luta de mulheres e jovens por maior liberdade. $O$ caminho é longo, mas a esperança no futuro do Irã continua a alimentar a professora de literatura inglesa, que deixou seu País, mas jamais deixará para trás as memórias de sua Teerã.

\subsection{QUEIMADA VIVA: DEPOIMENTO DE UMA SOBREVIVENTE}

Souad, hoje, é uma mulher que luta pelo fim dos chamados "crimes de honra" ao redor do mundo, tendo escrito o livro Queimada viva, que agora apresentamos. Baseada em sua experiência pessoal, ela, que sequer possui este nome e que não pode declarar o país da Europa em que vive, com medo de que sua família a encontre, denuncia a prática de atos brutais contra as mulheres em nome da defesa da honra, após ter sobrevivido milagrosamente a uma tentativa de homicídio, autorizada por seus próprios pais, em virtude de ter engravidado antes de se casar.

Nascida em um aldeia da Cisjordânia, governada por rígidos padrões de comportamento, Souad cresceu como todas as garotas da região, sonhando com um casamento que a libertasse do jugo paterno (apesar de ter consciência de que o marido poderia ser ainda pior que o genitor) e temendo ser tachada de charmuta pela comunidade em que vivia. Uma charmuta é uma mulher sem honra, e que por conseguinte desonra toda a sua família, merecendo a pena capital, ou seja, o assassinato, para que seus familiares recuperem o prestígio na comunidade. Uma garota, segundo Souad:

(...) deve andar depressa, a cabeça curvada para o chão, como se estivesse contando os passos. Seu olhar não pode levantar-se, nem vagar à esquerda ou à direita do caminho, pois se seu olho encontrasse o de um homem, toda a aldeia a chamaria de charmuta. $^{18}$

${ }^{18}$ SOUAD. Queimada viva: um documento, p. 9.

Revista Brasileira de Direito Internacional, Curitiba, v.6, n.6, jul./dez.2007 
As mulheres na terra de Souad tinham menos valor que um animal. Elas eram proibidas de freqüentar a escola, não podiam sair sozinhas de casa e sofriam espancamentos constantes, seja de pais e irmãos, seja dos maridos. A vida de uma mulher, ali, pertencia sempre a algum homem, responsável por seu destino. Nascer mulher era uma maldição, chega a dizer Souad, narrando uma cena de sua infância, quando presenciou sua mãe enforcando uma filha recém-nascida, apenas pelo fato de esta ser mulher, situação que deve ter ocorrido outras vezes naquela família, segundo a autora. Ela também vê a morte de uma irmã mais nova, assassinada pelo próprio irmão, mas nunca fica sabendo qual o motivo da morte; apenas sabe que os pais não estavam em casa, como sempre acontece nos crimes de honra.

Souad sonhava em se casar, mas a tradição impunha a obrigação de a irmã mais velha casar-se antes. A autora já estava com dezessete anos, quando se apaixonou por um vizinho que tinha interesse nela e, com medo de perdê-lo, entregou-se a ele mediante uma promessa de casamento. Grávida, foi abandonada pelo namorado e tornou-se a vergonha da família, que decidiu sem titubear: ela deve morrer. A tradição diz que o assassinato é sempre cometido por alguém da família, sem a presença dos pais. Seu cunhado foi o eleito para devolver a honra aos familiares. Ele iria queimá-la viva. Ela narra seu calvário: "De repente, senti uma coisa fria escorrendo pela minha cabeça. E logo em seguida estava coberta pelo fogo" ${ }^{\prime \prime}$.

Souad fugiu para a rua e foi socorrida em um hospital, onde foi deixada para morrer, porque ninguém ousa intrometer-se em questões de família. Ainda no nosocômio, ela deu à luz a seu filho, e sofreu uma tentativa de envenenamento por parte de sua mãe. A autora somente foi salva graças à ativista suíça Jacqueline Thibault, que conseguiu tirá-la com seu filho do país e levá-la à Europa, para tratar-se. Entregou seu menino para a adoção, mas hoje mantém contato com ele. Casou-se novamente, e atualmente trabalha na Organização Não-Governamental Surgir, cuja tarefa precípua é a denúncia dos crimes de honra. Souad assim define sua história, que serve de alerta para tantas outras mulheres e meninas que vivem à beira da morte:

${ }^{19}$ SOUAD. Queimada viva, p. 112.

Revista Brasileira de Direito Internacional, Curitiba, v.6, n.6, jul./dez.2007 


\begin{abstract}
Meu senhor, lá uma mulher não tem uma vida propriamente. Muitas moças são espancadas, estranguladas, queimadas, mortas. Para nós, lá, é perfeitamente normal. Minha mãe quis me envenenar para 'acabar' i trabalho do meu cunhado, e para ela, era normal, faz parte do mundo dela. A vida normal para nós, mulheres, é isso. Se você é espancada, é normal. Se é queimada, é normal, ou estrangulada, normal, ou maltratada, normal. A vaca e os carneiros, como dizia meu pai, são mais respeitados que as mulheres. Se não quisermos morrer, temos de nos calar, obedecer, rastejar, casar virgens e fazer filhos. Se eu não tivesse encontrado um homem no meu caminho, é essa a vida que eu teria tido. Minhas filhas se teriam tornado como eu, minhas bisnetas, como minhas filhas. Se tivesse continuado vivendo lá, me teria tornado normal, como minha mãe, que sufocou suas próprias filhas. Talvez que tivesse matado minha filha. Talvez tivesse deixado que a queimassem. Hoje eu acho isso uma monstruosidade! Mas se tivesse ficado lá, teria feito a mesma coisa! ${ }^{20}$
\end{abstract}

\title{
3.4 MULHERES MUTILADAS
}

Khady, senegalesa que hoje vive na França, conta sua história no livro Mutilada, história que, ainda nos dias de hoje, continua a fazer parte da trajetória de vida de milhares de mulheres ao redor do mundo. a autora viveu em uma realidade distinta da de Souad, pois em sua sociedade, embora as mulheres fossem submetidas aos homens (haja vista a prática que iremos descrever abaixo), elas eram bem mais livres que na aldeia de Souad.

Khady descreve a poligamia como fenômeno comum e aceito sem reservas pelas mulheres de sua comunidade; ela mesma fora criada por várias avós, esposas de seu avô, e viveu com a presença de uma co-esposa na casa de seu marido. As meninas da aldeia casavam-se cedo (Khady casou-se aos treze anos), e o casamento civil não tinha qualquer valor para os membros da comunidade: os casamentos eram sempre realizados em família, e acordados pelos pais dos noivos. Os divórcios também somente dependiam de acordo entre os familiares.

Khady pertencia à etnia soninké, família na qual as mulheres deveriam ser purificadas ainda na infância, para garantir um bom casamento. Purificar significa excisar, ou seja, extirpar o clitóris da menina. O procedimento da

${ }^{20}$ SOUAD. Queimada viva, p. 203/204.

Revista Brasileira de Direito Internacional, Curitiba, v.6, n.6, jul./dez.2007 
excisão era praticado pela etnia das ferreiras, sempre com a concordância das mulheres da família e, claro, da aceitação tácita dos homens. Khady assim descreve sua mutilação, aos sete anos de idade:

\footnotetext{
Duas mulheres me agarraram e arrastaram para o quarto. Uma, atrás de mim, me segura a cabeça e seus joelhos esmagam meus ombros com todo o peso deles para que eu me mexa; a outra me segura os joelhos, com as pernas afastadas. (...) a mulher encarregada da operação dispõe de uma lâmina de barbear por menina, que as mães compraram para a ocasião.

Ela puxa com os dedos, o mais possível, o minúsculo pedaço de carne e corta como se cortasse um pedaço de carne de zebu. Infelizmente, é impossível para ela fazê-lo com um único gesto. Ela é obrigada a serrar. ${ }^{21}$
}

Ainda, segundo Khady, "é uma dor inexplicável, que não se parece com nenhuma outra" ${ }^{22}$, e que marcará toda sua vida, a ponto de torná-la uma ativista contra a disseminação da prática.

Seis anos depois, Khady é dada em casamento no lugar de sua irmã divorciada, que pode recusar-se a casar. O casamento é acertado pelos homens na mesquita, e meses mais tarde, o noivo, que morava na França, volta ao Senegal para a festa de casamento, e para exercer seus direitos de marido. A dor, em virtude da excisão, foi tamanha que Khady apagou da memória esse momento.

Ela foi levada para viver na França, após sua família burlar o sistema legal do Senegal, pois ela não tinha idade para casar-se. Porque freqüentava a escola antes de mudar-se, Khady consegue trabalhar e ser relativamente independente do marido, o que levará o casal a brigas, com agressões físicas constantes. Além disso, ela descobre que a razão mais forte para o marido querer filhos e a manutenção do casamento era o seguro social pago pelo governo francês às famílias humildes, o que a leva a exigir o divórcio perante os Tribunais franceses e também frente a seu pai, que em uma reunião acorda o divórcio da filha.

\footnotetext{
${ }^{21}$ KHADY. Mutilada, p. 17.

${ }^{22}$ KHADY. Mutilada, p. 17.
}

Revista Brasileira de Direito Internacional, Curitiba, v.6, n.6, jul./dez.2007 
Khady permite a excisão de três filhas, uma delas com apenas um mês de idade. No entanto, após a morte de uma menina na França, em virtude da mutilação, a prática começou a ser condenada e criminalizada, o que contribuiu decisivamente para $\mathrm{o}$ ingresso da autora na militância contra a mutilação genital feminina, ingressando numa organização chamada GAMS, e assim descreve seu trabalho:

É preciso fazer com que elas não deixem acontecer o mesmo com suas filhas, nascidas ou por nascer, a barbaridade que as fará sofrer pelo resto da vida. explicar também que a religião nunca impôs essa mutilação. E para isso precisamos do envolvimento dos chefes religiosos da África. Compete a eles desmontar a vasta mentira mantida há séculos, por ignorância dos textos. Na realidade, excisão ou infibulação são preconizadas pelos homens e executadas pelas mulheres, por razões erradas. ${ }^{23}$

A missão de Khady, hoje, consiste em denunciar essa prática tradicional que tanto sofrimento traz às mulheres, em nome da garantia da virgindade da noiva, ou de sua fidelidade, numa clara demonstração da submissão feminina às realidades machistas.

${ }^{23}$ KHADY. Mutilada, p. 151.

Revista Brasileira de Direito Internacional, Curitiba, v.6, n.6, jul./dez.2007 


\section{A PROTEÇÃo dOS DIREITOS DAS MULHERES E A DIVERSIDADE CULTURAL}

De todo o exposto até agora, dessume-se que a proteção da mulher no plano internacional é tema por demais complexo e umbilicalmente ligado à questão da diversidade cultural presente nas várias sociedades. Religião, moral e política são determinantes da maior ou menor garantia de direitos ao sexo feminino. A questão de gênero expressa, de forma contundente, a delicada problemática entre as concepções universalista e relativista dos direitos humanos, das quais nos ocuparemos agora.

A idéia de direitos humanos, do modo como conhecemos hoje, iniciouse com o movimento iluminista, que desenvolveu a concepção desses direitos como inatos ao homem, pelo simples fato de ser humano. Justamente por essa razão, esses direitos foram considerados como pertencentes a todos os homens, indistintamente. Nesse sentido, podemos afirmar que os direitos humanos surgiram e afirmaram-se como universais.

A concepção universalista dos direitos humanos aparece com maior nitidez na Declaração Universal dos Direitos Humanos, firmada no âmbito da ONU em 1948, ao proclamar que todos os seres humanos nascem livres e iguais em dignidade e direitos e que toda a pessoa pode invocar todos os direitos e liberdades da Declaração. A própria ONU possui, dentre suas funções, a de monitorar a situação dos direitos humanos no mundo, e as Convenções que compõem o Sistema Global de Proteção aos Direitos Humanos, como a CEDAW, também expressam o caráter universalista de defesa e reconhecimento desses direitos, na medida em que se destinam indistintamente a homens e mulheres, sem consideração das peculiaridades regionais.

A positivação internacional dos direitos humanos sempre levou em consideração seu caráter universal. Contudo, em tempos de globalização e num mundo pós-descolonização geográfica, a controvérsia entre relativismo e universalismo volta à agenda de discussões. Aqueles que defendem a concepção universal dos direitos humanos afirmam que, em nome do 
relativismo, muitas sociedades escondem barbáries e violações sistêmicas dos direitos de seus cidadãos. A idéia de um universalismo viria, portanto, como forma de garantia de dignidade humana, para assegurar um rol de direitos que possibilitasse uma vida digna a qualquer pessoa ${ }^{24}$.

Já os que se opõem ao universalismo asseveram que essa concepção nasceu de uma perspectiva eurocêntrica de direitos do homem, e que se desenvolveu sempre a partir de um ponto de vista ocidental, que tenta se impor ao restante do mundo, como única resposta correta. Logo, os críticos vêem o universalismo como instrumento de dominação de um modo de vida sobre os outros, e não em seu viés emancipatório ${ }^{25}$. Ademais, os direitos humanos alçados a valores universais, para aqueles que defendem o relativismo, ferem a soberania dos países ao determinar de antemão quais os direitos e de que forma devem ser garantidos pelo governo interno.

Contudo, a defesa dos direitos humanos, hoje, exige que se supere o embate entre universalistas e relativistas, em nome de uma proteção ampla desses direitos, inclusive o direito a ver respeitada sua cultura. Segundo Boaventura de Sousa Santos:

Trata-se de um debate intrinsecamente falso, cujos conceitos polares são igualmente prejudiciais para uma concepção emancipatória de direitos humanos. Todas as culturas são relativas, mas o relativismo cultural enquanto atitude filosófica é incorreto. Todas as culturas aspiram a preocupações e calores universais, mas o universalismo cultural, enquanto atitude filosófica é incorreto. Contra o universalismo, há que propor diálogos interculturais sobre preocupações isomórficas. Contra o relativismo, há que desenvolver critérios políticos para distinguir política progressista de política conservadora, capacitação de desarme, emancipação de regulação. ${ }^{26} 27$

\footnotetext{
${ }^{24}$ Cf. PIOVESAN, F. Direitos Humanos e o Direito Constitucional Internacional, p. 170-171: “(...) reagem os universalistas, alegando que a posição relativista revela o esforço em justificar graves casos de violações dos direitos humanos que, a partir do sofisticado argumento do relativismo cultural, ficariam imunes ao controle da comunidade internacional. Argumentam que a existência de normas universais pertinentes ao valor da dignidade humana é uma exigência do mundo contemporâneo."

${ }^{25}$ Cf. PIOVESAN, F. Direitos Humanos e o Direito Constitucional Internacional, p. 170: "Na análise dos relativistas, a pretensão de universalidade destes instrumentos simboliza a arrogância do imperialismo cultural do mundo ocidental, que tenta universalizar suas próprias crenças. A noção universal de direitos humanos é identificada como uma noção construída pelo modelo ocidental. O universalismo induz, nesta visão, à destruição da diversidade cultural."

${ }^{26}$ SANTOS, Boaventura de Sousa. Uma concepção multicultural de direitos humanos, p. 110111.
}

Revista Brasileira de Direito Internacional, Curitiba, v.6, n.6, jul./dez.2007 
Portanto, afirmar o universalismo como único meio de acabar com a "barbárie" praticada principalmente pelas sociedades menos "civilizadas" representa, sim, um modo de disseminação dos valores ocidentais, valores que também provém de uma cultura definida, porém, que muitas vezes são impostos a sociedades que deles não compartilham, ao menos não integralmente $^{28}$. É essa visão do universalismo como dogma que acaba por provocar a hostilidade das sociedades não-ocidentais frente à desconsideração da cultura como fonte dos direitos humanos.

Entretanto, a adesão às teorias relativistas leva à legitimação de muitas violações de direitos humanos supostamente em nome da diversidade cultural. É preciso atentar para o fato de que, muitas vezes, são os governantes que invocam a tese do relativismo cultural, útil a seus propósitos, mas não à garantia de direitos à população. Admitir que religião, moral, costumes tradicionais, sirvam como fundamento para a prática de atos que atinjam a dignidade das pessoas, certamente, não é a solução para a proteção dos direitos humanos.

A mescla entre as concepções universalista e relativista de direitos humanos, ao revés, pode trazer muitos avanços na defesa das garantias e na proteção dos direitos dos povos e de seus cidadãos. Primeiramente, porque a cultura é um elemento inafastável de qualquer concepção que se tenha acerca de direitos. Michael Freeman apresenta uma definição de cultura cuja citação faz-se oportuna: "I shall take 'culture' to refer the beliefs, values, norms, sentiments, and practices that give meaning and (at least in farourable cases)

\footnotetext{
${ }^{27}$ Nesse mesmo sentido, bem aponta IBHAWOH, Bonny. Cultural Relativism and Human Rights: Reconsidering the Africanist Discourse, p. 61: "In the final analysis, it is significant to note that tha universalism versus cultural relativism debate over the legitimacy and priorities of human rights can be misleading. It is useful in so far as it calls attention to the ways in which the notions of liberty and individualism cab be, and have been used to rationalise the abuses of capitalism. Is is laso useful in so far as it highlights how notions of equality and collectivism can be, and have been used as excuses for arbitrary and authoritarian governance."

${ }^{28}$ Como, p.ex., no caso turco, que, numa tentativa de "modernização" para facilitar o ingresso na União Européia, proibiu a utilização do véu em repartições públicas, inclusive nas Universidades, motivando o ingresso de uma muçulmana na Corte Européia de Direitos Humanos, que decidiu favoravelmente ao governo turco.
}

Revista Brasileira de Direito Internacional, Curitiba, v.6, n.6, jul./dez.2007 
value to human lives" ${ }^{\prime 29}$. O conteúdo desses valores e crenças é que varia, de sociedade para sociedade, e até mesmo dentro das diversas sociedades.

Jack Donnely acertadamente observa que a filiação a um universalismo ou a um relativismo radical não são atitudes prudentes. $O$ autor defende uma concepção de relativismo cultural fraco, que admite serem os direitos humanos direitos universais, mas que compreende ser a cultura como fonte de validade aos direitos afirmados, inclusive porque não se pode entender que valores e costumes sejam imutáveis, mas sim contingentes, o que é compatível com a afirmação de universalidade dos direitos aqui referidos. ${ }^{30}$

Da mesma forma, o que se defende aqui não é a adesão a alguma das correntes, como se representasse a única possibilidade de compreensão da temática, mas sim uma concepção de diversidade cultural que leve a um diálogo entre os diferentes modos de vida, e que, de forma construtiva, busque a ampliação da defesa desses direitos. Socorremo-nos novamente de Boaventura de Sousa Santos, quando ele propõe diálogos interculturais de direitos humanos, asseverando que "a tarefa central da política emancipatória do nosso tempo consiste em transformar a conceptualização e prática dos direitos humanos de um localismo globalizado num projeto cosmopolita" ${ }^{31}$, através de uma hermenêutica diatópica, que reconhece a incompletude intrínseca às diversas culturas e, dessa forma, busca "ampliar ao máximo a consciência de incompletude mútua através de um diálogo que se desenrola, por assim dizer, com um pé numa cultura e outro, noutra"32 33.

Essa tendência em se respeitar a diversidade cultural vem ganhando força inclusive nos instrumentos internacionais de proteção aos direitos

\footnotetext{
${ }^{29}$ FREEMAN, Michael. Human Rights and Real Cultures: Towards a Dialogue on 'Asian Values', [s.p.].

${ }^{30}$ Apud PIOVESAN, F. Direitos Humanos e o Direito Constitucional Internacional, p. 169. A temática é assim exposta em IBHAWOH, B. Cultural Relativism and Human Rights, p. 47: "Weak cultural relativism on the other hand, holds that human rights are prima facie universal, but recognises culture as an important source of exceptions in the interpretation of human rights."

${ }^{31}$ SANTOS, B. S. Uma concepção multicultural de direitos humanos, p. 113.

${ }^{32}$ SANTOS, B. S. Uma concepção multicultural de direitos humanos, p. 116.

${ }^{33}$ Interessante nesse sentido é a crítica que as sociedades orientais fazem à concepção ocidental de direitos humanos, por ser individualista e dar primazia absoluta aos direitos, em detrimento dos deveres e das responsabilidades que daí advém. Um diálogo que considerasse essa crítica como ponto de partida seria, certamente, benéfico a ambas as concepções. Nesse sentido, MUZAFFAR, Chandra. Islã e direitos humanos, p. 316-317.
}

Revista Brasileira de Direito Internacional, Curitiba, v.6, n.6, jul./dez.2007 
humanos, como na Declaração e Programa de Viena de 1993, que, apesar de reafirmar a universalidade dos direitos humanos, reconhece que as particularidades nacionais e regionais precisam ser levadas em consideração.

Tomando-se as considerações acima, é possível imaginar um caminho para a mudança de paradigma no que concerne aos direitos da mulher no plano internacional. Da leitura das histórias de vida e de luta das mulheres que viveram e sobreviveram às suas realidades opressoras, é possível ter uma visão muito clara da insuficiência do embate universalismo versus relativismo, para tornar suas vidas mais dignas. O relativismo cultural tornaria legítimas todas as violações dos direitos dessas mulheres, e, com o isolamento das culturas, pouca esperança haveria para elas e para suas conterrâneas. Mas essas mulheres forjam suas identidades em seus valores, em suas crenças, e a idéia do universalismo mais radical não comportaria a dimensão tamanha que a cultura possui na vida dessas pessoas ${ }^{34}$.

Dar voz a essas mulheres e meninas, e possibilitar a elas o conhecimento de sua real situação é a maneira de fazer com que queiram lutar para ver reconhecido o valor que elas possuem, e acabar com a submissão do sexo feminino ao sexo masculino. O diálogo entre culturas, sem pretensão de estabelecer uma delas como certa, seria de utilidade ímpar para o alcance desse fim, qual seja, libertar a mulher do jugo machista e patriarcal.

O grande número de países signatários da CEDAW, embora muitos deles com reservas substanciais à Convenção, revela, ao menos, uma esperança no sentido de se afirmar os direitos humanos das mulheres. $O$ compromisso internacional de cumprir os dispositivos do tratado é a luz de que a condição feminina precisa para continuar na luta pela efetivação de seus direitos.

\footnotetext{
${ }^{34}$ Como afirma MELLO, Celso Duvivier de Albuquerque. Curso de Direito Internacional Público, p. 788: "Não se pode negar o aspecto universal dos direitos humanos, mas eles também estão estreitamente vinculados às noções de nacionalidade e cidadania."
}

Revista Brasileira de Direito Internacional, Curitiba, v.6, n.6, jul./dez.2007 


\section{CONSIDERAÇÕES FINAIS}

O caminho para a conquista e efetivação dos direitos humanos ao redor do mundo é longo, mas passos importantes nesse sentido já foram dados. A constatação, em 1979, de que à condição feminina não bastavam os instrumentos gerais de proteção aos direitos humanos. A Convenção pela Eliminação de Todas as Formas de Discriminação contra a Mulher, nesse sentido, representa a consolidação de lutas dos movimentos feministas, na busca por maior dignidade e igualdade de condições e oportunidades às mulheres.

A CEDAW assume crucial importância como instrumento paradigma das reivindicações pela defesa do gênero feminino. Não apenas para os Estados-partes na Convenção, que se obrigaram a promover a igualdade entre os sexos em seus territórios. O fato de uma convenção como a CEDAW fazer parte da normativa internacional de direitos humanos significa a formação de uma consciência internacional no sentido de preservar e assegurar o exercício de direitos por parte das mulheres, o que representa efetivamente uma transformação de mentalidades, mormente se lembrarmos que durante grande parte da história conhecida da humanidade o sexo feminino foi subjugado ao poderio masculino.

Muita coisa mudou desde a adoção da Convenção. A China sediou o último grande encontro de direitos humanos das mulheres, em 1995, cujo enfoque principal foram os direitos sexuais. As denúncias internacionais contra os crimes de honra e as mutilações genitais lentamente surgem efeito. Países muçulmanos mudam suas leis ${ }^{35}$. Esses indicativos de mudanças permitem que se tenha esperanças nos bons resultados de um diálogo que leve à melhoria na vida de mulheres como Khady, Souad, Azar e daquelas cujas histórias vieram à tona com Xinran.

\footnotetext{
${ }^{35}$ Como a promulgação do Novo Código de Família no Marrocos, o qual, embora ainda não tenha conseguido equiparar os direitos de homens e mulheres no casamento e na família, resultando de um consenso entre o movimento feminista e os setores conservadores, traz avanços significativos, especialmente em se tratando de um Estado muçulmano. Nesse sentido, ver GARRUDO, Alicia del Olmo. Democracia y derechos de las mujeres en Maruecos: el nuevo Código de la Familia.
}

Revista Brasileira de Direito Internacional, Curitiba, v.6, n.6, jul./dez.2007 
A atenção maior há que se voltar para o constante perigo da imposição de um modo de vida a outro, sob o argumento retórico da defesa dos direitos humanos $^{36}$. Não se olvide que a promoção da diversidade cultural é também uma garantia de que essas mulheres, além de verem afirmados seus direitos, poderão ver respeitadas suas identidades culturais.

\footnotetext{
${ }^{36}$ Cf. HINKELAMMERT, Franz J. La inversión de los derechos humanos: el caso de John Locke, p. 80: "Los derechos humanos de transformaron en una agressividad humanitaria: violar los derechos humanos de aquellos que los violan. (...) Esta es la inversión de los derechos humanos, en cuyo nombre se aniquila a los propios derechos humanos."
}

Revista Brasileira de Direito Internacional, Curitiba, v.6, n.6, jul./dez.2007 


\section{REFERENCIAS}

BOBBIO, Norberto. A Era dos Direitos. Trad. Carlos Nelson Coutinho. Rio de Janeiro: Campus, 1992.

CANÇADO TRINDADE, Antonio Augusto. A proteção internacional dos direitos humanos: fundamentos jurídicos e instrumentos básicos. São Paulo: Saraiva, 1991.

CENTRO DE JUSTIÇA GLOBAL. Programa de Capacitação "Marcio Baccarin Possebon": Treinamento em mecanismos internacionais de direitos humanos e estratégias de mídia, 2002.

CONSEIL DE L'EUROPE. La protection des femmes contre la violence:

Recommandation Rec (2002)5 du Comité des Ministres aux Etats membres sur la protection des femmes contre la violence adoptée le 30 avril 2002 et Exposé des motifs. Strasbourg, 2002.

FREEMAN, Michael. Human Rights and Real Cultures: Towards a Dialogue on 'Asian Values'. In: Netherlands Quarterly of Human Rights, 1998.

GARRUDO, Alicia del Olmo. Democracia y derechos de las mujeres en Maruecos: el nuevo Código de la Familia. Aequalitas: Revista Jurídica de Igualdad de Oportunidedas entre Mujeres y Hombres. Zaragoza: Universidad de Zaragoza, n. 16, p. 19-27, enero/junio-2005.

GOYOS JUNIOR, Durval de Noronha. O Novo Direito Internacional Público e o Embate contra a Tirania. São Paulo: Observador Legal, 2005.

HINKELAMMERT, Franz J. La inversión de los derechos humanos: el caso de John Locke. In: FLORES, Joaquín Herrera (ed.). El vuelo de Anteo: derechos humanos y crítica de la razõn liberal. Bilbao: Desclée de Brouwer, 2000, p. 79113.

HUMAN RIGTHS COMMITTEE. General Comment No 28: Equality of rights between men and women, (Art. 3), 2000.

IBHAWOH, Bonny. Cultural Relativism and Human Rights: Reconsidering the Africanist Discourse. In: Netherlands Quarterly of Human Rights, 2001.

KHADY. Mutilada. Colaboração de Marie-Thérèse Cuny. Trad. Rejane Janowitzer. Rio de Janeiro: Rocco, 2006.

MELLO, Celso Duvivier de Albuquerque. Curso de Direito Internacional Público. Rio de Janeiro: Renovar, 2003. 
MUZAFFAR, Chandra. Islã e direitos humanos. Trad. Roberto Cataldo Costa. In: BALDI, César Augusto (org.). Direitos Humanos na sociedade cosmopolita. São Paulo: Renovar, 2004, p. 309-322.

NAFISI, Azar. Lendo Lolita em Teerã: uma memória nos livros. Trad. Tuca Magalhães. São Paulo: A Girafa, 2004.

PIOVESAN, Flávia. Direitos Humanos e o Direito Constitucional Internacional. 6.ed. São Paulo: Max Limonad, 2004.

SANTOS, Boaventura de Sousa. Uma concepção multicultural de direitos humanos. Revista Lua Nova, n. 39. São Paulo: Cedec, 1997, p. 105-123.

SOUAD. Queimada viva. Colaboração de Marie-Thérèse Cuny. Trad. Clóvis Marques. São Paulo: Planeta do Brasil, 2004.

STEINER, Henry J.; ALSTON, Philip. International Human Rigths in context: Law, Politics, Morals. 2.ed. Oxford: Oxford University, [s.d.].

XINRAN. As boas mulheres da China: vozes ocultas. Trad. Manoel Paulo Ferreira. São Paulo: Companhia das Letras, 2003. 